\title{
Michael Kling
}

\section{Sprachrisiken im Privatrechtsverkehr}

\author{
Die wertende Verteilung sprachenbedingter Verständnisrisiken im Vertragsrecht
}

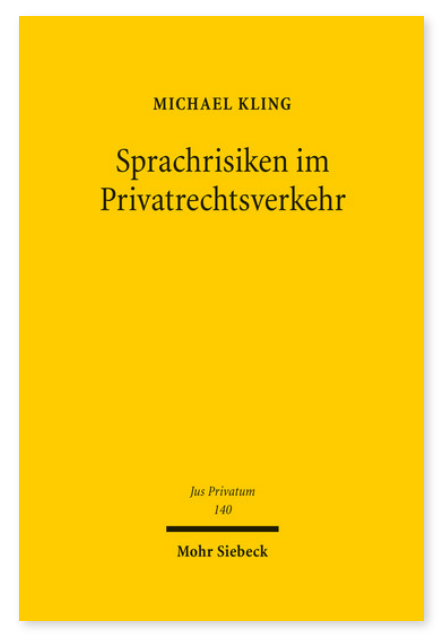

2008. XXXI, 694 Seiten. JusPriv 140

ISBN 978-3-16-151217-9

DOI 10.1628/978-3-16-151217-9

eBook PDF 149,00€

ISBN 978-3-16-149777-3

Leinen $149,00 €$
Michael Kling behandelt die Frage nach der Zuweisung des sogenannten »Sprachrisikos« im Privatrechtsverkehr und damit ein Rechtsproblem, welches bis heute als »ungelöst « bezeichnet wird und das eine »bislang vollkommen unberechenbare Rechtsprechung " hervorgerufen hat.

Im ersten Abschnitt behandelt der Autor bedeutsame Vorfragen aus dem Europarecht und dem Internationalen Privatrecht und untersucht das System und die allgemeinen Prinzipien des Privatrechts.

Im zweiten Abschnitt, dem Schwerpunkt der Untersuchung, erörtert der Autor das Problem der Sprachrisiken unter dem Blickwinkel des materiellen deutschen Privatrechts, das gemäß dem IPR als einschlägig unterstellt wird. Da es keine allgemeine gesetzliche Regelung zur Lösung von sprachenbedingten Mißverständnissen enthält, unternimmt der Autor eine detaillierte Analyse der Vorschriften des Allgemeinen Teils des BGB sowie des Allgemeinen Schuldrechts.

Darüber hinaus behandelt der Autor die Abgabe und den Zugang von Willenserklärungen, die Auslegung von

Willenserklärungen und Verträgen, die Anfechtung von Willenserklärungen - einschließlich der Frage nach der Existenz und Reichweite sprachenbezogener Aufklärungspflichten - und schließlich das Recht der Allgemeinen Geschäftsbedingungen. Hier geht er auch auf Fragen des internationalen Handelsverkehrs ein, deren Lösung sich nach Gemeinschaftsrechtsakten (wie der EuGVVO) oder Internationalen Übereinkommen (wie dem Luganer Übereinkommen) vollzieht. Abschließend bietet er eine längere thesenartige Zusammenfassung der wichtigsten Ergebnisse.

Michael Kling Geboren 1972; Studium der Rechtswissenschaften in Mainz; 2000 Promotion; 2008 Habilitation; seit 2009 ordentlicher Professor an der Philipps-Universität in Marburg.

Jetzt bestellen:

https://mohrsiebeck.com/buch/sprachrisiken-im-privatrechtsverkehr-9783161512179?no_cache=1

order@mohrsiebeck.com

Telefon: +49 (0)7071-923-17

Telefax: +49 (0)7071-51104 